\title{
Convergência e discrepância em documentos norteadores dos estágios supervisionados obrigatórios em fisioterapia: uma revisão integrativa
}

\section{Convergence and discrepancies in guiding documents of the mandatory supervised practice in physiotherapy: an integrative review}

\section{Cristiane Cavalcante Moreira' ${ }^{1}$ (1) \\ Sumaia Midlej Sá ${ }^{2}$ (1) \\ Ana Sueli Teixeira de Pinho ${ }^{3}$ (1) Helena Fraga-Maia ${ }^{4}$ (1)}

\begin{abstract}
1,3Universidade do Estado da Bahia (Salvador). Bahia, Brasil. kikamoreira1006@gmail.com, anasuelipinho@yahoo.com.br Universidade do Estado da Bahia, Universidade Católica do Salvador (Salvador). Bahia, Brasil. sumaia.midlej@gmail.com ${ }^{4}$ Autora para correspondência. Universidade do Estado da Bahia (Salvador). Bahia, Brasil. helenafragamaia@gmail.com
\end{abstract}

RESUMO | INTRODUÇÃO: O estágio supervisionado obrigatório constitui-se em um componente curricular que integra o processo formativo do graduando em Fisioterapia. Todavia, a despeito de sua relevância como construto legal e normativo, os documentos oficiais não dão suporte suficiente à unificação dos critérios de sua realização, o que pode ocasionar a ocorrência de práticas irregulares. OBJETIVO: Identificar as discrepâncias e pontos de convergência existentes nos documentos oficiais e relatos de pesquisas que norteiam os estágios supervisionados obrigatórios em Fisioterapia. MÉTODOS: Revisão integrativa da literatura com consulta às bases de dados PubMed, SciELO, Biblioteca Virtual em Saúde e Periódicos Capes, e aos documentos oficiais do Conselho Federal de Fisioterapia, Conselho Nacional de Saúde, Ministério da Educação e Associação Brasileira de Ensino em Fisioterapia. RESULTADOS: Foram analisados 15 artigos publicados entre os anos de 2002 e 2017 e sete documentos oficiais que abordam os estágios, a práxis pedagógica e as normas legais no contexto da Fisioterapia. CONCLUSÃo: Existem discrepâncias em relação ao número de estudantes por supervisor de estágio e por turno de prática, à identidade do profissional, sua presença durante o treinamento e intervalo temporal entre a teoria e o estágio curricular obrigatório. Já como pontos de convergência podem ser pontuados o reconhecimento do estágio enquanto uma prática curricular obrigatória e didático-pedagógica e o momento em que o estudante deverá ser estimulado a desenvolver autonomia e responsabilidade profissional, interação com a equipe multiprofissional e habilidade no manejo dos pacientes.

PALAVRAS-CHAVE: Estágios. Fisioterapia. Leis. Resoluções.
ABSTRACT | INTRODUCTION: The mandatory supervised practice is a curricular component that integrates the training process of the undergraduate student in Physiotherapy, however, despite its relevance as a legal and normative construct, the official documents do not provide sufficient support for the unification of the criteria for its completion, which can cause irregular practices to occur. OBJECTIVE: Identify the discrepancies and points of convergence in existing official documents and research reports that guide the mandatory supervised internships in Physiotherapy. METHODS: Integrative literature review with a consultation to the databases PubMed, SciELO, Virtual Health Library, and Capes Periodicals, and to the official documents of the Federal Council of Physiotherapy, National Council of Health, Ministry of Education, and the Brazilian Association of Teaching in Physiotherapy. RESULTS: 15 articles published between 2002 and 2017 were analyzed, as well as seven official documents that address internships, pedagogical praxis, and legal norms in the context of Physiotherapy. CONCLUSION: There are discrepancies concerning the number of students per internship supervisor and practice shift, the professional identity, their presence during training, and the time interval between theory and the mandatory curricular internship. As points of convergence, the recognition of the internship as a mandatory and didactic-pedagogical curricular practice and the moment when the student should be encouraged to develop autonomy and professional responsibility, interaction with the multidisciplinary team, and ability to manage patients can be scored.

KEYWORDS: Nonmedical Internship. Physiotherapy Specialty. Laws. Resolutions. 


\section{Introdução}

O estágio supervisionado obrigatório é uma das principais atividades de profissionalização do graduando com práticas educativas monitoradas previstas no Projeto Pedagógico do Curso (PPC). Entendido como um componente curricular que integra o processo formativo, o estágio é desenvolvido no ambiente de trabalho visando à preparação para o ofício produtivo de estudantes que estejam frequentando o ensino regular em instituições de educação superior ${ }^{1}$. Trata-se de um componente curricular fundamental à formação profissional em que os estudantes são continuamente desafiados, assim como em outras etapas do curso, a articular a teoria e a prática ${ }^{2-7}$. É um laboratório que contextualiza, por meio de situações reais, em diferentes níveis de atenção e de complexidade, e com diversos recursos terapêuticos, uma prática no âmbito do mundo do trabalho $2-4, z, 8$, prática esta que está sujeita aos marcos regulatórios de cada profissão.

De modo geral, os documentos que regulamentam os estágios supervisionados obrigatórios em Fisioterapia, tais como a Lei $n^{\circ} 11.788 / 2008$, a Resolução do Conselho Nacional de Saúde, sobre as Diretrizes Curriculares Nacionais do Curso de Graduação em Fisioterapia (DCN), e as Resoluções do Conselho Federal de Fisioterapia e Terapia Ocupacional (COFFITO) são diretivas para a organização dos estágios nos Cursos de Graduação em Fisioterapia. No entanto, quando os gestores, aqui denominados Coordenadores de Cursos, procuram seguir as orientações postuladas por estas, enfrentam dificuldades diante da falta de consenso entre elas.

Dentre os aspectos que têm sido alvo de discussões em fóruns específicos do campo da Fisioterapia, como a Associação Brasileira de Ensino em Fisioterapia ${ }^{8}$, há discrepâncias sobre a quantidade de alunos por turma de estágio, a identidade do supervisor e sua presença constante durante a prática supervisionada, além do intervalo temporal entre os componentes curriculares específicos e o estágio supervisionado obrigatório. Todos esses critérios normativos, portanto, são debatidos entre as IES e as organizações de saúde em que são realizados os estágios supervisionados obrigatórios. Assim, a despeito de sua relevância como construtos legais e normativos, os do- cumentos oficiais, por não apresentarem consenso, acabam concorrendo para a ocorrência de práticas irregulares. A emergência das fragilidades existentes entre os referidos documentos fundamenta o aprofundamento do debate e a identificação das dissonâncias existentes. Assim, o objetivo deste estudo foi identificar os conflitos existentes nos documentos oficiais e relatos de pesquisas que norteiam os estágios supervisionados obrigatórios em Fisioterapia, apontando pontos de convergência e discrepância entre eles.

\section{Material e Métodos}

Trata-se de um estudo de revisão integrativa da literatura realizado a partir da análise de artigos científicos publicados em periódicos indexados e de documentos que dispõem sobre o estágio supervisionado. Foram adotadas as seguintes etapas para a constituição da revisão integrativa da literatura: definição da pergunta de pesquisa, dos critérios de inclusão e exclusão, seleção das produções nas principais bases de dados de acordo com os critérios de elegibilidade, escolha dos artigos pertinentes, organização e classificação temática, considerando as características em comum, análise crítica dos achados, identificando diferenças e ausência de consenso, interpretação e exposição dos resultados com reflexões pertinentes.

A busca ocorreu no período de fevereiro a dezembro de 2019 nos portais/bases eletrônicas de dados Scientific Eletronic Library Online (SciELO), Biblioteca Virtual em Saúde (BVS), Medical Literature Analysis and Retrieval System on-line (MEDLINE/PUBMED), portal Periódicos Capes (Coordenação de Aperfeiçoamento de Pessoal de Nível Superior), nos endereços eletrônicos do Conselho Federal de Fisioterapia (COFFITO), do Conselho Nacional de Saúde (CNS), bem como os sites do Ministério da Educação (e-MEC) e da Associação Brasileira de Ensino em Fisioterapia (ABENFISIO). Buscas adicionais foram realizadas nas listas de referências dos estudos analisados. Foram utilizados os seguintes descritores: Estágio, Fisioterapia, Leis e Resolução, contidos nas bases Ciências da Saúde (DeCS) e Medical Subject Headings (MeSH) nos idiomas português e inglês, utilizando os operadores booleanos "AND" (E) e "OR" (OU). 
Foram adotados como critérios de inclusão artigos observacionais, dissertações ou teses que abordassem os estágios obrigatórios supervisionados em Fisioterapia, que estivessem disponíveis integralmente quer no idioma português, inglês ou espanhol e que tivessem sido publicados no período de 2002 a 2017. Já para a inclusão dos documentos oficiais das instituições federais não foi delimitado intervalo temporal. Foram excluídas produções do tipo anais, editoriais, resenhas e comentários.

A busca resultou em 189 documentos e, dentre estes, sete documentos oficiais do COFFITO, CNE, e-MEC e ABENFISIO. Após leitura dos títulos e resumos foi realizada a leitura completa dos documentos por dois autores independentes e na ocorrência de discordância entre os mesmos, um terceiro pesquisador foi acessado para emitir parecer decisório. Na sequência, 33 artigos foram lidos na integra e 18 foram excluídos por se tratarem de relatos de opinião ou de caso(s).

\section{Resultado}

Foram localizados seis artigos na base SciELO, 47 na Biblioteca Virtual em Saúde (BVS), 28 na base MEDLINE/PUBMED, 95 nos Periódicos Capes e quatro documentos nos sites oficiais do COFFITO, um do CNS, um da ABENFISIO e um do MEC. Após a exclusão de trabalhos repetidos e da aplicação dos critérios de elegibilidade, foram selecionados 15 artigos científicos e sete leis e resoluções. A Figura 1 representa o processo de seleção dos relatos de pesquisas.

Dentre os quinze artigos selecionados, sete foram publicados em língua inglesa e os demais em língua portuguesa. Após a análise, foi possível constatar que seis (06) abordavam o número de alunos por supervisor, cinco (05) a identidade do supervisor, quatro (04) a presença do supervisor na prática supervisionada e sete (07) o intervalo entre os componentes curriculares teóricos e práticos no currículo acadêmico.

Dentre os documentos oficiais, foram incluídos: a) a Lei do Estágio 11.788/081ㄹ, b) a Lei $n^{\circ} 4$ do CNE/

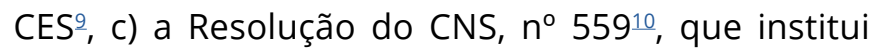
as DCN do Curso de Graduação em Fisioterapia, d) Resolução do COFFITO, $n^{\circ} 43111$, que dispõe sobre o exercício acadêmico de estágio obrigatório em Fisioterapia, de setembro de 2013; e) a Resolução COFFITO, n' 444논 que dispõe sobre os Parâmetros Assistenciais Fisioterapêuticos nas diversas modalidades prestadas pelo fisioterapeuta, f) a Resolução

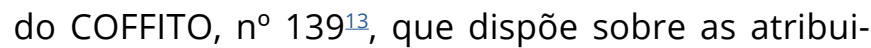
ções do Exercício de Responsabilidade Técnica nos campos assistenciais de Fisioterapia, e finalmente, g) a Resolução do COFFITO, $n^{\circ} 153^{14}$, que altera a relação de 1 preceptor para um contingente máximo de 6 alunos, diferente do que estava contido na Resolução COFFITO 139/92. 


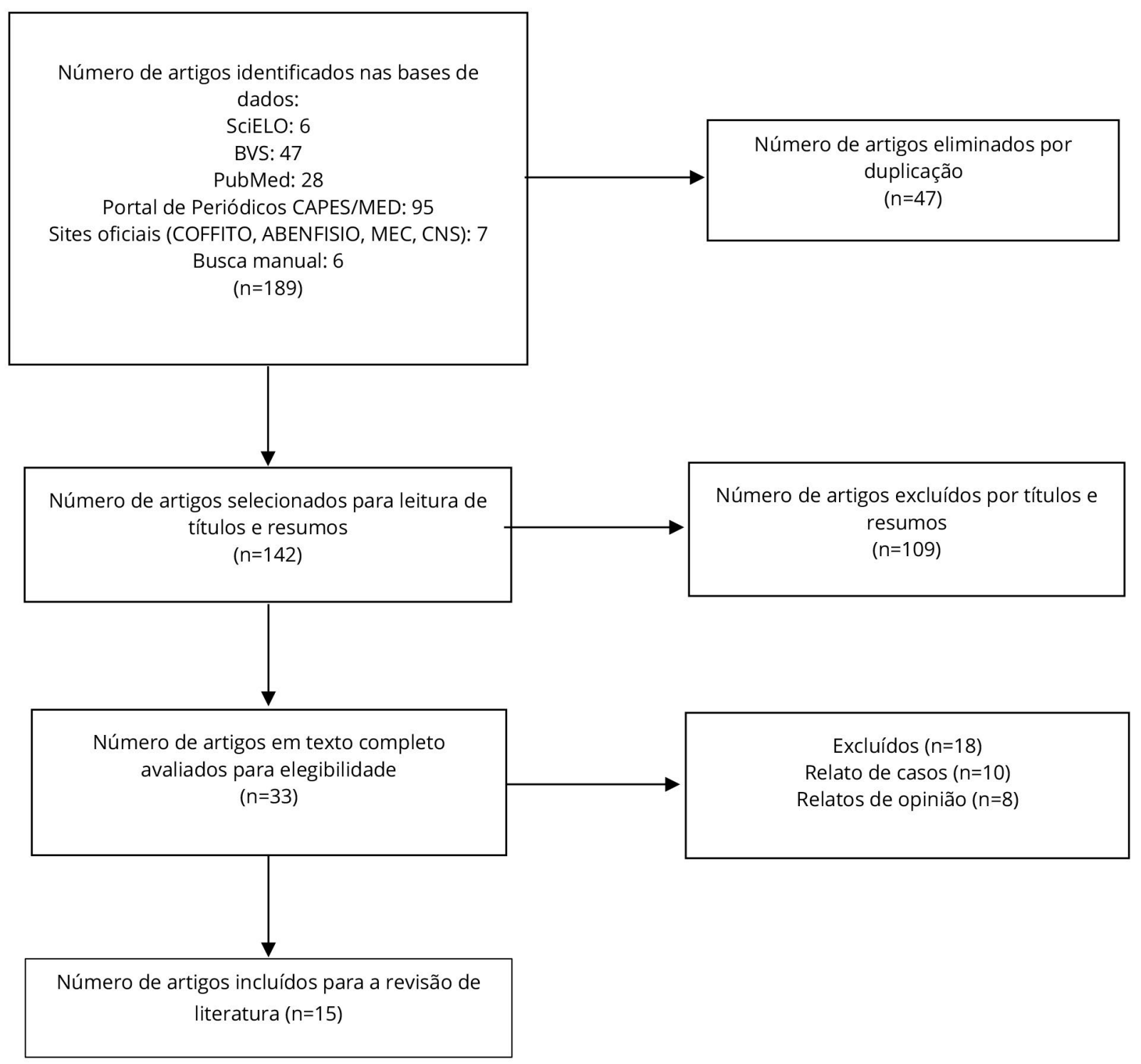

Fonte: Elaboração própria.

Com relação à quantidade de alunos por supervisor, foram localizados documentos oficiais que apresentam discrepâncias entre si. A Resolução 431 do COFFITO'11, no seu artigo terceiro, define que, para o estágio curricular obrigatório, deverá ser respeitada a relação de um (01) docente supervisor fisioterapeuta contratado pela IES para até seis (06) estagiários, tendo em vista orientá-los e supervisioná-los simultaneamente em todos os cenários de atuação, e de, no máximo, três (03) estagiários por docente supervisor fisioterapeuta em comunidade (domicílio), Unidades de Terapia Intensiva, Semi-Intensiva e Centro de Tratamento de Queimados. Tais recomendações contrapõem-se ao que determina a Lei 11.788/08¹, que preconiza até 10 estagiários por supervisor. Ressalta-se que a presença de estagiários nos serviços de Fisioterapia, em qualquer nível de atenção à saúde, não modifica os parâmetros assistenciais dos profissionais lotados nos referidos serviços conforme a Resolução COFFITO 4311ㅡ, artigo $8^{\circ}$, capítulo II, que define o número de pacientes por fisioterapeuta, não devendo este ser alterado em função da presença de estagiários nos serviços. Tais aspectos são corroborados pela Resolução COFFITO no $444^{12}$ que preconiza que, nos diversos setores dos serviços, o número de pacientes por fisioterapeuta dependerá do local em que este estiver alocado. 


\begin{tabular}{|c|c|c|c|c|}
\hline Autor/ano/ & Citação & Idioma/país & Objetivo & Principais resultados \\
\hline \multicolumn{5}{|c|}{ Número de alunos por supervisor } \\
\hline $\begin{array}{l}\text { Gustafsson et al., } \\
2016\end{array}$ & 22 & Inglês/Austrália & $\begin{array}{l}\text { Explorar a educação prática na perspectiva dos programas } \\
\text { universitários de terapeutas ocupacionais. }\end{array}$ & $\begin{array}{l}\text { Aprendizagem tradicional e co-supervisão com } 2 \text { (dois) ou mais supervisores por } \\
\text { aluno, experiências com grupos modelos com um (1) supervisor para dois (2) ou } \\
\text { mais alunos e supervisão de um (1) aluno para } 2 \text { (dois) alunos mais jovens no curso. }\end{array}$ \\
\hline Gribble et al., 2016 & 17 & Inglês/Austrália & $\begin{array}{l}\text { Investigar alterações nos escores de inteligência emocional } \\
\text { dos estudantes de terapia nos estágios finais de seus } \\
\text { programas de estágios curriculares. }\end{array}$ & $\begin{array}{l}\text { Os alunos eram supervisionados com uma variedade de modelos, incluindo um } \\
\text { profissional supervisionando um aluno, vários alunos com um supervisor, um aluno } \\
\text { sendo supervisionado por vários profissionais, e canais autodirecionados com } \\
\text { mínima supervisão direta. }\end{array}$ \\
\hline Larin et al., 2005 & 19 & $\begin{array}{l}\text { Inglês/ Canadá e } \\
\text { Emirados } \\
\text { Árabes }\end{array}$ & $\begin{array}{l}\text { Descrever as reflexões de estudantes de Fisioterapia de uma } \\
\text { cultura do Oriente Médio durante seus estágios clínicos e } \\
\text { compará-los às reflexões de estudantes de Fisioterapia de } \\
\text { uma cultura ocidental. }\end{array}$ & $\begin{array}{l}\text { Pequenos grupos de ensino tutorial baseado em resolução de problemas e alunos } \\
\text { do sexo masculino e feminino são agrupados em turmas diferentes com atuação } \\
\text { em áreas distintas do campus. Um dos aspectos que afetaram o } \\
\text { autodesenvolvimento foi a forma de realização do feedback dado pelo supervisor e } \\
\text { este, }\end{array}$ \\
\hline $\begin{array}{l}\text { Domingues et al., } \\
2009\end{array}$ & 6 & Português/Brasil & $\begin{array}{l}\text { Comparar as avaliações de docentes /supervisores de } \\
\text { diferentes especialidades para alunos em estágio clínico. }\end{array}$ & $\begin{array}{l}\text { Diferentes docentes avaliarem o mesmo aluno, com critérios muito diferentes, pode } \\
\text { gerar consequências negativas, tanto para o docente quanto para o discente. }\end{array}$ \\
\hline $\begin{array}{l}\text { Robson e Kitchen, } \\
2007\end{array}$ & 26 & Inglês/Londres & $\begin{array}{l}\text { Avaliar a percepção dos estudantes de Fisioterapia sobre as } \\
\text { habilidades e abordagens usadas nos ambientes de } \\
\text { interações interprofissionais. }\end{array}$ & $\begin{array}{l}\text { Escuta ativa, negociação e discussão nos espaços formais foram vistos como } \\
\text { positivos pelos estudantes e são influenciados pelo numero de alunos por } \\
\text { supervisor. }\end{array}$ \\
\hline $\begin{array}{l}\text { Hilton e Morris, } \\
2001\end{array}$ & 18 & Inglês/Londres & $\begin{array}{l}\text { Avaliar a percepção dos alunos sobre as habilidades e } \\
\text { abordagens usadas e os fatores que afetam as interações } \\
\text { interprofissionais no ambiente clínico. }\end{array}$ & $\begin{array}{l}\text { Discentes acompanhados por apenas um profissional específico e sem a visão } \\
\text { multidisciplinar referiram sentir falta das discussões interdisciplinares e dos pontos } \\
\text { de vista de diferentes profissionais. }\end{array}$ \\
\hline \multicolumn{5}{|c|}{ Identidade do supervisor } \\
\hline Araújo et al., 2010 & 8 & Português/Brasil & $\begin{array}{l}\text { Conceituar e definir, de acordo com a ABENFISIO, os estágios } \\
\text { obrigatórios e não obrigatórios em Fisioterapia. }\end{array}$ & $\begin{array}{l}\text { O supervisor de estágio deverá ser fisioterapeuta, ter vínculo trabalhista na IES } \\
\text { como docente, de acordo com sua situação e plano de carreira, ser cem por cento } \\
\text { presencial. }\end{array}$ \\
\hline Gribble et al. 2016 & 17 & Inglês/Austrália & $\begin{array}{l}\text { Investigar alterações nos escores de inteligência emocional } \\
\text { dos estudantes de terapia nos estágios finais de seus } \\
\text { programas de estágios curriculares. }\end{array}$ & $\begin{array}{l}\text { Um facilitador interprofissional é contratado pela IES em tempo integral para } \\
\text { supervisionar coortes de alunos interprofissionais. }\end{array}$ \\
\hline $\begin{array}{l}\text { Gaiad \& Sant'Ana, } \\
2005\end{array}$ & 20 & Português/Brasil & $\begin{array}{l}\text { Analisar a eficiência do Estágio Supervisionado da Graduação } \\
\text { em Fisioterapia na formação do profissional Fisioterapeuta a } \\
\text { partir da visão do egresso. }\end{array}$ & $\begin{array}{l}\text { Os professores fisioterapeutas têm a responsabilidade de facilitar o raciocínio } \\
\text { clínico de seus estudantes através da autonomia que os mesmos possuem durante } \\
\text { o período de estágio procurando formar fisioterapeutas mais reflexivos. }\end{array}$ \\
\hline Boucaut et al., 2008 & 21 & Inglês/Austrália & $\begin{array}{l}\text { Compreender a visão da indústria em receber estagiários de } \\
\text { Fisioterapia. }\end{array}$ & $\begin{array}{l}\text { Coordenadores de IES que desejarem vagas para estágios supervisionados em } \\
\text { Fisioterapia em indústrias terão dificuldades para contratar profissionais } \\
\text { fisioterapeutas. }\end{array}$ \\
\hline Batiston et al., 2017 & 29 & Português/Brasil & $\begin{array}{l}\text { Relatar a experiência da implantação de uma } \\
\text { nova proposta pedagógica para o Estágio Supervisionado em } \\
\text { Fisioterapia na AB }\end{array}$ & $\begin{array}{l}\text { Professores fisioterapeutas realizam a supervisão direta dos estudantes juntamente } \\
\text { com os fisioterapeutas do curso, que também desenvolvem a supervisão } \\
\text { compartilhada no território. }\end{array}$ \\
\hline \multicolumn{5}{|c|}{ Presença do supervisor na prática supervisionada } \\
\hline $\begin{array}{l}\text { Gustafsson et al., } \\
2016\end{array}$ & 22 & Inglês/Austrália & $\begin{array}{l}\text { Explorar a educação prática na perspectiva dos programas } \\
\text { universitários de Terapeutas Ocupacional }\end{array}$ & $\begin{array}{l}\text { A maioria dos programas oferecem experiências de supervisão em campo, mas são } \\
\text { também observadas supervisão à distância ou próxima ao local do estágio. }\end{array}$ \\
\hline Gaida et al., 2015 & 15 & Inglês/Austrália & $\begin{array}{l}\text { Identificar e analisar as características dos relatos de } \\
\text { incidentes envolvendo estudantes de Fisioterapia durante o } \\
\text { estágio clínico. }\end{array}$ & $\begin{array}{l}\text { Lesões ocorreram com maior frequência quando o supervisor não estava próximo } \\
\text { do aluno (aproximadamente } 50 \% \text { versus } 20 \% \text { ). Preparar o discente para trabalhar } \\
\text { independentemente pode entrar em conflito com o dever de cuidado da } \\
\text { universidade em proteger alunos e pacientes. }\end{array}$ \\
\hline
\end{tabular}


Tabela 1. Análise descritiva dos relatos de pesquisa selecionados (conclusão)

\begin{tabular}{|c|c|c|c|c|}
\hline $\begin{array}{l}\text { Autor/ano/ } \\
\text { Presença do supervis }\end{array}$ & $\begin{array}{l}\text { Citação } \\
\text { sor na prát }\end{array}$ & $\begin{array}{l}\text { Idioma/país } \\
\text { ca supervisionada }\end{array}$ & Objetivo & Principais resultados \\
\hline $\begin{array}{l}\text { Gaiad \& Sant'Ana, } \\
2005\end{array}$ & 20 & Português/Brasil & $\begin{array}{l}\text { Analisar a eficiência do Estágio Supervisionado do Curso de } \\
\text { Graduação em Fisioterapia na formação do profissional } \\
\text { Fisioterapeuta a partir da visão do egresso }\end{array}$ & $\begin{array}{l}\text { Reiteram que a presença do supervisor é necessária ao processo de aprendizagem } \\
\text { do aluno e à tomada de decisões. }\end{array}$ \\
\hline Batiston et al., 2017 & 29 & Português/Brasil & $\begin{array}{l}\text { Relatar a experiência da implantação de uma } \\
\text { nova proposta pedagógica para o Estágio Supervisionado em } \\
\text { Fisioterapia na AB. }\end{array}$ & $\begin{array}{l}\text { Professores fisioterapeutas realizam a supervisão direta juntamente com os } \\
\text { fisioterapeutas do curso, que também desenvolvem a supervisão }\end{array}$ \\
\hline \multicolumn{5}{|c|}{ Intervalo de tempo entre as disciplinas específicas e os estágios supervisionados } \\
\hline Boucaut et al., 2008 & 21 & Inglês/Austrália & $\begin{array}{l}\text { Compreender a visão da indústria em receber estagiários de } \\
\text { Fisioterapia. }\end{array}$ & $\begin{array}{l}\text { Os estágios são realizados apenas no último ano da graduação. Há grande aceitação } \\
\text { por parte da indústria que ganha com serviços de estudantes quase profissionais } \\
\text { reduzindo custos e os alunos logram com formação profissional e experiência em } \\
\text { ambientes reais de trabalho. }\end{array}$ \\
\hline Viana et al., 2012 & 25 & Português/Brasil & $\begin{array}{l}\text { Investigar a opinião dos estudantes de Fisioterapia em } \\
\text { relação ao estágio extracurricular e a influência dessa prática } \\
\text { para sua formação profissional. }\end{array}$ & $\begin{array}{l}\text { Concentração dos estágios no período final do curso, motivando a procura por } \\
\text { estágios não obrigatórios no decorrer da formação com a justificativa que esta } \\
\text { prática propiciaria melhor qualificação para o mercado e maior preparação para a } \\
\text { fase dos estágios obrigatórios. }\end{array}$ \\
\hline $\begin{array}{l}\text { Silva \& Da Ros, } \\
2007\end{array}$ & 2 & Português/Brasil & $\begin{array}{l}\text { Analisar a formação acadêmica do profissional de } \\
\text { Fisioterapia em relação ao PSF sob a ótica dos atores } \\
\text { envolvidos nesta formação. }\end{array}$ & $\begin{array}{l}\text { Somente na fase do estágio (último ano da graduação) é que entraram em contato } \\
\text { com a realidade relacionada ao campo da saúde coletiva, porém de forma } \\
\text { insuficiente. }\end{array}$ \\
\hline $\begin{array}{l}\text { Gaiad \& Sant'Ana, } \\
2005\end{array}$ & 20 & Português/Brasil & $\begin{array}{l}\text { Analisar a eficiência do Estágio Supervisionado do Curso de } \\
\text { Graduação em Fisioterapia na formação do profissional } \\
\text { Fisioterapeuta a partir da visão do egresso. }\end{array}$ & $\begin{array}{l}\text { Os estudantes consideram a carga-horária insuficiente, tornando-os inseguros em } \\
\text { algumas situações. Assim como não dão a devida importância aos conteúdos } \\
\text { curriculares quando vistos na faculdade. Só se dão conta da sua importância após } \\
\text { [iniciarem] a sua prática profissional. }\end{array}$ \\
\hline $\begin{array}{l}\text { Teixeira \& Oliveira, } \\
2007\end{array}$ & 4 & Português/Brasil & $\begin{array}{l}\text { Revisar a base legal para os estágios em Fisioterapia e } \\
\text { explorar as contradições que há entre diferentes } \\
\text { documentos na atualidade. }\end{array}$ & $\begin{array}{l}\text { Os estágios têm início no } 40 \text { semestre em apenas } 10 \% \text { dos cursos; a maioria inicia } \\
\text { no } 60 \text { ou } 70 \text { semestre ( } 70 \%) \text {. Há cursos que iniciam seus estágios obrigatórios } \\
\text { apenas no final do curso, ou seja, na } 80 \text { fase (10\%) ou na } 9 \text { o fase (10\%). }\end{array}$ \\
\hline Seriano et al., 2013 & 5 & Português/Brasil & $\begin{array}{l}\text { Verificar a percepção de estudantes do Curso de Fisioterapia } \\
\text { de uma IES pública, na cidade de Teresina (PI), sobre sua } \\
\text { formação para prestação de serviços na área de atenção } \\
\text { básica no SUS. }\end{array}$ & $\begin{array}{l}\text { Os estágios supervisionados ocorrem no último ano do curso, sendo divididos em } \\
\text { ambulatoriais e em saúde pública no } 9 \text { período, e hospitalares no } 10 \text { período. }\end{array}$ \\
\hline Batiston et al., 2017 & 29 & Português/Brasil & $\begin{array}{l}\text { Relatar a experiência da implantação de uma } \\
\text { nova proposta pedagógica para o Estágio Supervisionado em } \\
\text { Fisioterapia na AB. }\end{array}$ & $\begin{array}{l}\text { Supervisão direta dos estudantes dos } 9^{\circ} \text { e } 10^{\circ} \text { semestres de Fisioterapia em duas } \\
\text { Unidades Básicas de Saúde da Família. }\end{array}$ \\
\hline
\end{tabular}


Sobre a identidade do supervisor, observa-se ampla concordância entre os documentos com relação à exigência de que as práticas sejam realizadas por profissionais fisioterapeutas $s^{8,10,11,29}$, independente $d a$ etapa de formação do estudante e se o estágio é ou não obrigatório, mas não há consenso quanto à sua vinculação com as IES que ofertam os estágios já que a Lei $11.788^{1}$ permite que o profissional contratado pela instituição de saúde, não necessariamente o docente da IES, atue como supervisor de estágio. Em contraponto, a Resolução COFITTO 431, reiterada pelas recomendações da ABENFISIO, define que o estágio curricular obrigatório deverá ter supervisão direta de um docente fisioterapeuta vinculado ao curso e devidamente contratado pela IES.

A supervisão durante as atividades de estágios é obrigatória ${ }^{8,10,11,29}$, mas o distanciamento do supervisor tem também um papel didático em conferir independência e autonomia ao estudante prestes a iniciar suas atividades profissionais. Todavia, o docente precisará avaliar continuamente quais estudantes poderão atuar com supervisão mais distante e quais precisarão de acompanhamento mais próximo com o intuito, inclusive de evitar iatrogenias, já que IES tem o dever de proteger tanto os pacientes quanto os alunos ${ }^{15}$. Outras formas de supervisão têm surgido e opções de estágios à distância supervisionado por profissionais com diferentes formações ou por alunos mais adiantados no curso de Fisioterapia já são realidade na Austrália.

Quanto ao intervalo temporal existente entre a oferta de disciplinas específicas e a oferta do estágio supervisionado obrigatório, observou-se que há um distanciamento entre a oferta de disciplinas básicas, específicas e obrigatórias, respeitando-se a maturidade do discente, como sugere a DCN de Fisioterapia art. 13, incisos I e II, e também as resoluções da ABENFISIO de 2012, apesar de que, para os estudantes, a distância é maior do que deveria ser ou do que realmente desejam para sua formação.

\section{Discussão}

Os documentos e os relatos de pesquisas sobre os estágios obrigatórios supervisionados permitem a identificação de concepções distintas que são utilizadas de acordo com os interesses dos gestores das IES, e que poderão estar mais ou menos comprometidas com as leis do mercado ou da educação. Em alguns aspectos, as referências favorecem interpretações dúbias, facilitando a adoção de modelos mais simplificados, ou seja, aqueles que envolvem um número maior de discentes por supervisor, supervisão à distância ou supervisão eventual. Pereira e Alves ${ }^{16}$ destacaram que existem diversas concepções teóricas atribuídas ao estágio, que também é uma disciplina cheia de burocracia, e que nem sempre aproxima o discente da sua prática clínica. Esta realidade é acentuada no ensino a distância (EAD), e pela falta de explicitação de sua organização, faz com que esse componente curricular possa ter pouca relevância, ou seja, ser pouco valorizada pelas IES.

O estágio deve proporcionar aos futuros profissionais a compreensão da complexidade das práticas institucionais, superando a separação entre teoria e prática. Ou seja, não se pode colocar no estágio supervisionado obrigatório a única possibilidade de prática durante o curso. É necessário que, desde o início da formação, haja uma correlação da teoria com a prática nas diversas fases de amadurecimento do discente, além de sua gradativa aproximação com a realidade em que atuará ${ }^{14}$. Espera-se que as disciplinas acadêmicas possibilitem aos estudantes o desenvolvimento de competências e habilidades, como a construção de sentido de um vocabulário próprio, o uso de recursos de análise que envolvam o diagnóstico cinético-funcional, o conhecimento básico dos processos relacionados à intervenção fisioterapêutica, os recursos tecnológicos empregados, assim como as relações interpessoais com a equipe multiprofissional. Tais competências e habilidades permitirão ao estudante entender melhor o que ocorre com os pacientes, quer estes estejam em empresas ou instituições de saúde. 
As $\mathrm{DCN}$ ํ, ao abordarem as questões relativas à educação permanente, orientam que os profissionais de saúde devam ser capazes de aprender continuamente, tanto em sua formação, quanto em sua prática. Desta forma, estes devem aprender continuamente e ter responsabilidade e compromisso com a sua educação e a formação das futuras gerações de profissionais, propiciando as condições para que haja benefício mútuo, inclusive estimulando e desenvolvendo a mobilidade acadêmico-profissional, a formação e a cooperação por meio de redes nacionais e internacionais.

\section{Número de alunos por supervisor}

A despeito do contido nas Resoluções do COFFITO $431 \frac{11}{11} 139^{13}, 153^{14}$ e das recomendações da ABENFISIO $\stackrel{8}{ }$, que preconizam de três a seis alunos por supervisor, a depender do local em que ocorre o estágio, a Lei $11.788 / 08^{1}$ sugere a possibilidade de até 10 estagiários simultaneamente por docente. Estas discrepâncias têm implicações de cunho prático, que se relacionam com os custos da docência e com outras, de cunho didático, tendo inúmeras repercussões no processo de ensino-aprendizagem.

A realização dos estágios hospitalares é, em geral, reportada como geradora de ansiedade, receio ou medo por parte dos estudantes que estão finalizando a graduação. Para além da ansiedade gerada pelo desconhecido, pode haver influência negativa na competência emocional de estudantes de Fisioterapia, devido à supervisão clínica deficiente, conflito entre estudante e supervisor ou, ainda, por reprovação no estágio clínico ${ }^{17}$. Segundo Gribble et al. ${ }^{17}$, quando estudantes em situações emocionalmente vulneráveis se encontram em ambientes novos e desafiadores, onde se espera que promovam, sob pressão, assistência aos pacientes, além de um contato adequado com a equipe de saúde, o nível de estresse se eleva. Por outro lado, um supervisor que precisa acompanhar grande número de estudantes pode também se sentir mais estressado e, reagindo a muitos estímulos simultâneos, não só ofertar menor atenção, como também apresentar impaciência, gerando conflitos com seus alunos. Tais comportamentos, para alguns alunos, pode gerar uma redução importante da assertividade, da capacidade de resolução de problemas, de controle de impulsos, de auto atualização e de tolerância ao estresse. Portanto, preconiza-se que os supervisores sejam sensíveis para perceber as dificuldades emocionais dos discentes e assim, possam identificar e acompanhar os mais suscetíveis de forma acolhedora; para tal, deve-se considerar a possibilidade de se ter turmas com um número menor de alunos.

Outro fator que pode afetar emocionalmente os estudantes na fase dos estágios curriculares obrigatórios é a possível falta de unidade na forma como são avaliados por diferentes supervisores e, quanto maiores forem as turmas de estágios, mais facilmente estes acontecimentos poderão ocorrer. A definição de quais domínios de competência os alunos devem atingir pode também não estar claramente definida ou compreendida pelos supervisores. Domingues et al. $\underline{6}$ salientaram que 0 fato de diferentes docentes avaliarem o mesmo aluno com critérios muito diferentes pode gerar consequências negativas, tanto para o docente quanto para o discente. Para muitos supervisores, é mais fácil avaliar as competências técnicas do que as emocionais. No entanto, não está claro ou unificado o critério sobre quanto um aluno deve conhecer para ser aprovado. Muitas vezes, nas fichas de avaliação, apenas um ou dois pontos abordam aspectos não técnicos, como a ética profissional, a frequência ou a forma de abordar o paciente ${ }^{18}$. Além da falta de unidade nas avaliações realizadas pelos supervisores, também a expectativa que estes colocam sobre os alunos pode influenciar na avaliação. Alunos com maiores competências prévias podem ser mais cobrados do que alunos considerados como tendo fraco background. No estudo de Larin et al. $\frac{17}{}$, os discentes relataram o quanto três aspectos afetaram seu autodesenvolvimento: o comportamento dos outros estudantes, a forma de realização do feedback dado pelo supervisor e a resposta clínica de seus pacientes. Demonstraram, ainda, que ganhavam mais confiança à medida que o estágio avançava, mas que um feedback mal direcionado do supervisor exercia grande impacto negativo direto na sua autoconfiança. 
Os estágios clínicos podem ser de fundamental importância, pois podem fornecer oportunidades para um aprendizado interprofissional continuado e de forma apropriada ao ambiente clínico. Escuta ativa, negociação e discussão nos espaços formais foram vistos como positivos pelos estudantes entrevistados por Robson e Kitchen ${ }^{13}$. Da mesma forma, ainda segundo estes autores, os estudantes podem achar que o resultado é positivo quando a colaboração do supervisor é regular, planejada e formal, que são características próprias dos ambientes hospitalares. Há que se considerar, por sua vez, que a colaboração do supervisor é influenciada também pelo quantitativo de alunos sob seu comando.

Já em ambientes menos formais, como os estágios em comunidade, em que o número de alunos por supervisor deveria ser de três para um, usualmente, na prática, esse número é aumentado pela falta de fiscalização. Hilton e Morris ${ }^{18}$ reportaram que os discentes, acompanhados apenas por um profissional específico e sem a visão multidisciplinar característica das equipes encontradas em ambientes hospitalares, referiram sentir falta das discussões interdisciplinares e dos pontos de vista diferentes dos profissionais envolvidos na equipe. Por outro lado, em ambiente de cuidados intensivos, o contato insuficiente entre os membros da equipe também é caracterizado como uma barreira, já que o supervisor deve mediar situações novas, frequentemente críticas nas quais o estudante precisa ser proativo ${ }^{19}$.

\section{Identidade do supervisor}

De acordo com a Resolução 559/201710 e a Resolução $\mathrm{n}^{\circ} 431$ do COFFITO ${ }^{11}$, podem atuar como supervisores de estágios curriculares profissionais fisioterapeutas devidamente contratados pelas IES, enquanto, pela Lei 11.7881 , poderão ser supervisores os profissionais indicados pelas instituições concedentes para exercer tais práticas. As diferentes concepções dos documentos supracitados permitem que muitas IES se utilizem destes expedientes para não contratar supervisores de estágio, autorizando a atuação de profissionais do serviço como supervisores. Tal prática se faz incoerente na medida em que é necessário ao estágio um plano de trabalho docente, que se constitui em documento didático-pedagógico, além de propiciar questionamentos acerca do grau de comprometimento do supervisor com a formação do futuro profissional 20 .
A formação do estudante é uma das prioridades das IES e quando o supervisor fisioterapeuta é funcionário da instituição se espera que ele conheça o PPC do curso em que está inserido, participe das reuniões do curso e colabore com os feedbacks dos estudantes nas reuniões de colegiado e de professores. Diferentemente, supervisores do serviço podem não ter vínculo com a IES, com a formação estudantil e, principalmente, com as transformações sociais e o perfil profissiográfico do discente, divergindo das recomendações da ABENFISIO e da Resolução 431.

Assim, a grande questão é a identidade do supervisor de estágio. Em muitos casos, é um profissional alheio às discussões acadêmicas e com remuneração abaixo, e distinta, daquela do corpo docente. As horas pagas pelas IES são para o indivíduo estar dentro dos locais de prática, não oferecendo qualquer tipo de remuneração para sua qualificação e aproximação dos processos acadêmicos. Quando o supervisor de estágio está na categoria de professor, os proventos são altos, o que proporciona que o mesmo possa contribuir com a IES, já que é remunerado para atuar na formação acadêmica. Sendo assim, aqui cabe uma reflexão sobre quem contratar. As habilidades exigidas precisam ser claramente definidas nos processos avaliativos e nas bancas de seleção de supervisores, assim como explicitadas na hora da contratação, respeitando-se características importantes desses profissionais. Dessa forma, isso facilitará o seu compromisso com um ensino superior de qualidade.

Sobre esses aspectos relacionados às características do supervisor, as recomendações da ABENFISIO8 são claras e estabelecem que o supervisor de estágio deve ser fisioterapeuta, ter vínculo trabalhista na IES, como docente, e ter seu plano de carreira. Deve, ainda, estar inscrito regularmente no Conselho Regional de Fisioterapia (CREFITO) de sua circunscrição, fazendo-se presente durante todo o período do estágio e destinando parte da carga horária para a pesquisa e a produção científica, além de estar subordinado a um coordenador de estágio, contratado pela respectiva IES.

Com as mudanças no mundo do trabalho, novas configurações podem ser detectadas atualmente com mais facilidade, o que não significa necessariamente a conquista de avanços no processo de ensino-aprendizagem. Na Austrália, por exemplo, ainda que o fisioterapeuta tenha um papel bem estabelecido na saúde ocupacional e a formação acadêmica 
seja valorizada como importante na preparação para tal, muitos supervisores de estágios supervisionados em empresas não são fisioterapeutas ${ }^{21}$. Boucaut ${ }^{21}$, em estudo qualitativo conduzido com supervisores de estágio, reportou que coordenadores de IES que desejarem vagas para estágios supervisionados de Fisioterapia em indústrias, enfrentarão dificuldades para contratar profissionais fisioterapeutas. Neste citado estudo, dentre os nove entrevistados, apenas dois eram fisioterapeutas. Como resultado, três temas foram enfatizados após as análises dos dados, o benefício mútuo, tanto por alunos quanto para os locais de prática por ganho de experiência em situações reais, a transferência e aquisição de recursos, conhecimentos e habilidades fornecido pelos estudantes, e finalmente, que o investimento do tempo em treinar foi compensado com ganho de tempo para a organização anfitriã.

\section{Presença do supervisor na prática supervisionada obrigatória}

No art. $1^{\circ}$ da Resolução $431^{10}$, constata-se que o estágio curricular obrigatório deverá ter supervisão direta de docente fisioterapeuta do curso, devidamente contratado pela IES, com carga horária específica para esta atividade, estando devidamente registrado no Sistema COFFITO/CREFITOS. Este artigo coloca a presença do supervisor no local do estágio curricular como imprescindível. Gaiad e Sant'Anna ${ }^{20}$ também reiteraram que a presença do supervisor é necessária ao processo de aprendizagem do aluno e à tomada de decisões. Vale salientar que supervisão presencial pode também significar proteção para os discentes e pacientes ${ }^{15}$.

Gaida et al..$\frac{15}{5}$ enfatizaram que o desafio é equilibrar diariamente a supervisão acadêmica com vistas a prover autonomia progressiva do estudante, uma vez que os preceptores estão formando os futuros profissionais. Neste sentido, a proximidade do supervisor implica maior ou menor preparação do estudante para vivenciar situações clínicas adversas. Estar mais atento aos atendimentos prestados pode possibilitar interferências prontas e rápidas no sentido de reduzir incidentes ou procedimentos iatrogênicos tanto para o estudante, quanto para o cliente nos serviços que são cenários das práticas de ensino. Em suma, a proximidade do supervisor pode estar relacionada com a menor ocorrência de incidentes. $\mathrm{Na}$ investigação conduzida por Gaida et al. ${ }^{15}$, cerca de $50 \%$ dos incidentes em estágios clínicos, que resultaram em lesões, ocorreram quando o supervisor estava ausente, enquanto aproximadamente $20 \%$ ocorreram quando estes estavam presentes. Apesar da diferença estimada por estes autores não ter sido estatisticamente significante, sabe-se que o supervisor, estando mais perto, é capaz de corrigir e conduzir situações pontuais necessárias ao crescimento do formando, especialmente em situações mais graves que exigem maior rapidez de resolução, como nos casos de atendimentos em UTI e emergências hospitalares. Cabe, portanto, identificar os alunos mais vulneráveis e inseguros e ofertar supervisão mais próxima e cuidadosa até que desenvolvam boa capacidade para a realização de diagnósticos mais acurados e planejamentos terapêuticos mais efetivos.

Os novos desafios em saúde, marcadamente vinculados às normas do mercado e ao financiamento da formação, estão colocando a supervisão direta em segundo plano e o supervisor para orientar a distância ou, até mesmo, os estudantes do último ano supervisionando os mais jovens na formação. Outras formas de substituição da prática supervisionada foram reportadas na Austrália por Gustafsson et al. $\underline{22}$ com as simulações do ambiente real, sessões educacionais e acesso à biblioteca. Uma possível justificativa para tais condutas seria o fato de que a obrigatoriedade das práticas poderia tornar o curso sem sustentabilidade financeira. Objetivamente, as organizações/empresas que aceitam sediar estágios têm interesses próprios. Caso esses interesses não sejam alcançados, não há motivo para a manutenção dos mesmos. De forma geral, o entendimento da empresa, que justifica a incorporação de estudantes ao ambiente laboral, é de que estes se comuniquem bem, demonstrem uma boa habilidade em pesquisa e observação, ajam de forma profissional e ética, respeitando a confidencialidade dos dados dos pacientes e podendo trabalhar de forma autônoma e como parte do time. Essas são as habilidades comerciais na hora de fechar as parcerias, tornando as empresas em centros de organização das atividades de currículo da universidade.

Observa-se também que as IES vêm mudando os seus PPC, na tentativa de adequar a formação dos futuros profissionais de saúde à realidade que atualmente se apresenta. Há uma necessidade de se ter uma universidade mais comprometida com novas formas de pensar e de formar as suas futuras elites ${ }^{23}$. 
Para esses autores, a superação do desafio posto, qual seja a função social da universidade na formação dos futuros profissionais é, por um lado, tornálos competentes e comprometidos com a realidade e por outro, reconhecer as comunidades como espaços aprendentes a serem por eles transformados ${ }^{23}$. Vale destacar, portanto, que as IES devem empregar esforços constantes para se certificarem do perfil profissiográfico dos futuros egressos dos cursos de Fisioterapia, se este foi estabelecido em consonância com as premissas filosóficas, pedagógicas e epidemiológicas dos diferentes campos de estágio, e se as práticas profissionais formadoras estão contextualizadas à localidade em que a IES está inserida². Nesse sentido, Pedra et al. $\underline{\underline{28}}$ enfatizaram que a formação do fisioterapeuta deve ser alinhada aos princípios e diretrizes do SUS viabilizadas por meio de atividades que promovam a integração ensino-serviço e vivências práticas nos três níveis de atenção à saúde.

\section{Intervalo de tempo entre as disciplinas específicas e os estágios supervisionados}

Nos documentos e relatos de pesquisas consultados, as matrizes curriculares dos Cursos de Fisioterapia apontaram que os estágios são programados para serem ofertados no final da formação. Há uma predominância das disciplinas básicas no início e de disciplinas específicas das especialidades no intercurso da formação, o que suscita, muitas vezes, por parte dos discentes, a busca de experiências em estágios curriculares não obrigatórios, com a alegação de que há uma grande distância entre a teoria e a prática ${ }^{24}$. Este intervalo temporal pode ser observado de duas formas. A primeira seria aquela a que os discentes mais referem, que é a necessidade de realização precoce de estágios, a outra refere-se à definição conceitual que admite o estágio supervisado obrigatório atrelado ao grau de maturidade do estudante, o que justifica a sua inclusão no final da formação. Segundo as recomendações da ABENFISIO ${ }^{\circledR}$, o estágio deverá ocorrer após o discente vivenciar práticas e fundamentos teóricos capazes de habilitá-lo ao exercício profissional gradualmente, já que a prática do estágio supervisionado integra a trajetória final de formação. Não foram localizados dados nacionais mais recentes, mas, em 2017, Teixeira e Oliveira ${ }^{4}$ reportaram que em Santa Catarina apenas $10 \%$ dos cursos iniciavam os estágios no quarto semestre, mas a maioria (70\%) no sexto ou sétimo, e 10\% no final do curso.
A despeito das inúmeras discussões acerca dos estágios supervisionados, as evidências científicas disponíveis sugerem um descontentamento dos discentes com relação aos mesmos $2,20,25$. Em estudo realizado por Viana et al. $\frac{25}{5}$ as principais queixas dos alunos eram relacionadas com a concentração das atividades práticas no período final do curso, o que motivava a procura por estágios não obrigatórios no decorrer da formação com a justificativa de que esta prática propiciaria uma melhor qualificação para o mercado e maior preparação para a fase dos estágios obrigatórios. Dados adicionais dessa pesquisa apontam ainda que $90,2 \%$ dos discentes procuraram atividades curriculares não obrigatórias motivados pela necessidade de adquirir experiência, $6,6 \%$ pela remuneração, 1,6\% pela curiosidade e 1,6\% por influência da família e amigos ${ }^{25}$. A viabilização de oportunidades práticas mais precoces, decorrentes das parcerias que promovam integração ensino-serviço-comunidade, pode permitir que o estudante de Fisioterapia seja capacitado para, no futuro, ampliar sua capacidade de intervenção, experienciando sob supervisão multidisciplinar, ações promoção de saúde, de prevenção de doenças, de reabilitação e de recuperação do estado de saúde, com respeito aos direitos do paciente ${ }^{29}$. Atividades puramente teóricas sobre saúde coletiva não propiciam aprendizagem, como bem salientaram Seriano et al. $\underline{5}$ ao reportarem que, segundo a percepção dos estudantes, o conhecimento sobre o SUS só foi possível no final da graduação com os estágios supervisionados. Alerta-se, entretanto, para a necessidade de fiscalização do CREFITO e do Ministério da Educação (MEC), bem como de questionamento da responsabilidade das empresas ou clínicas que oferecem estágios obrigatórios ou não obrigatórios, uma vez que irregularidades, do ponto de vista legal, podem ser observadas.

Silva e Da Ros², no estudo cujo objetivo foi analisar a formação acadêmica do profissional de fisioterapia em relação ao Programa de Saúde da Família (PSF) sob a ótica dos atores envolvidos nesta formação, reportaram insatisfação dos graduandos que estavam cursando o estágio supervisionado obrigatório no ultimo ano do curso na área de saúde coletiva. Segundo os discentes, os mesmos tiveram contato com a disciplina relacionada a esta área somente na fase inicial do curso com abordagem apenas teórica e, portanto, houve um grande intervalo entre a teoria e a prática gerando insegurança e desconhecimento revelado apenas com o início das atividades do referido estágio. 
O modelo de formação em que a prática do estágio supervisionado acontece apenas no final da graduação, fortalece a formação disciplinar, fragmentada e tecnicista, com consequente não comprometimento com o SUS e com as necessidades da população. Para estes autores, a universidade deve contribuir não somente através da formação profissional, como também na composição de cenários e situações que promovam a interdicisplinaridade, a multiprofissionalidade do trabalho, a apropriação do sistema de saúde vigente no país e a interação entre a universidade e a sociedade? .

A prática dos estágios, quando bem direcionada, contribui para a construção de um perfil profissional focado não apenas na reabilitação. Permite aos acadêmicos vivenciarem o processo de integralidade na atenção à saúde e o direcionamento das atividades, considerando o paciente e suas peculiaridades, realizando atividades voltadas a um olhar globalizado do sujeito, mesmo que esses estágios sejam hospitalares. Como exemplo dos aspectos citados, em outro estudo realizado, estudantes do último período do curso de Fisioterapia realizaram atividades, como educação e promoção em saúde, discussão de casos clínicos, atendimento e avaliação de pacientes nas enfermarias de um hospital que atende pelo Sistema Único de Saúde (SUS), e envolveram os pacientes, seus acompanhantes e a equipe de saúde da unidade hospitalar ${ }^{24}$. Experiências deste tipo podem ampliar a capacidade de intervenção dos profissionais, no sentido de alargar a integralidade da atenção ${ }^{27}$. No entanto, no início do curso, outras ações podem ser realizadas em termos de prevenção primária, o que pode viabilizar a diminuição da distância entre a teoria e a prática.

A introdução de vivências práticas nas disciplinas iniciais do curso, quer seja através de recursos de computação, de discussão de casos clínicos, de modelos anatômicos que representem pacientes em situações clínicas mais ou menos complexas, assim como por meio da leitura de lâminas e da análise de artigos científicos, desde os momentos iniciais do curso, podem motivar os discentes e torná-los mais ativos em sua própria formação. Tais procedimentos podem prepará-los melhor para o ingresso nos estágios supervisionados e obrigatórios e evitar inserção precoce em instituições não comprometidas com a formação profissional.
O importante é que os estágios possam contribuir de forma significativa, operando transformações na realidade de alunos, pacientes, equipes e família. Quando inserido no estágio supervisionado obrigatório, o discente se apresenta como um sujeito portador de um arcabouço teórico maior e mais amadurecido e poderá oferecer uma contribuição importante à sociedade. Vale ressaltar que parte dos estágios supervisionados obrigatórios acontece nas clínicas-escolas que, mesmo não vinculadas ao SUS, atendem a populações carentes com perfis semelhantes aos encontrados nas unidades de baixa e média complexidade. Como essas clínicas cumprem um calendário acadêmico, em alguns períodos do ano, a prática pode ser descontinuada e o tratamento do paciente é interrompido sempre que ocorrem as férias acadêmicas. É mister salientar que estas interrupções no atendimento comprometem os sujeitos em tratamento, a aprendizagem dos discentes, assim como as pesquisas em andamento.

\section{Considerações Finais}

Os resultados permitem concluir que existem discrepâncias e convergências entre os relatos de pesquisas e documentos oficiais que regem os estágios obrigatórios em Fisioterapia. As principais discordâncias ocorrem em relação ao número de estudantes por supervisor de estágio na graduação em Fisioterapia, a identidade do supervisor e à sua presença ou não durante as atividades práticas, ao intervalo temporal entre a teoria e o estágio curricular obrigatório e quanto ao número de alunos por turno de prática supervisionada. Já o reconhecimento de que o estágio, como uma prática curricular obrigatória e didáticopedagógica, é o momento em que o estudante deve ser estimulado a desenvolver autonomia e responsabilidade profissional, interação com a equipe multiprofissional e habilidade no manejo dos pacientes são os pontos convergentes. Estas questões impõem uma reflexão sobre a atual formação em Fisioterapia e as tendências nacionais e internacionais de flexibilização das normas e aproximação das questões de mercado. Em outros países, já podem ser evidenciadas a presença de supervisores não fisioterapeutas e a supervisão a distância. Tais práticas poderão ser adotadas no território nacional, caso não haja uma ampla discussão política e um forte posicionamento 
em defesa dos interesses da classe, como de órgãos como o COFFITO, a ABENFISIO e outros. O quadro sanitário da pandemia do Covid-19 pode propiciar novas visões de como os estágios supervisionados obrigatórios poderão ocorrer a partir de então, mas salienta-se a necessidade de que sejam regidos por marcos regulatórios nacionais unificados e voltados para o atendimento dos princípios do SUS. Novos estudos poderão caminhar nessa perspectiva com o objetivo de fortalecer a profissão e conhecer mais de perto os parâmetros que são utilizados nos Cursos de Fisioterapia em todo o território nacional. Discutir de forma mais embasada as atividades de estágio, além de como é feito e o porquê, comparando as micro e macrorregiões de um país continental poderá contribuir para minimizar as assimetrias entre as regiões levando-se em consideração os aspectos socioculturais de cada uma.

\section{Contribuições das autoras}

Moreira C participou da concepção e desenho da pesquisa; obtenção, análise e interpretação dos dados, redação e revisão crítica do manuscrito. Fraga-Maia $\mathrm{H}$ participou da concepção e desenho da pesquisa, análise e interpretação dos dados, redação e revisão crítica do manuscrito. Sá SMP e Pinho AST participaram da análise e interpretação dos dados, redação e revisão crítica do manuscrito.

\section{Conflitos de interesses}

Nenhum conflito financeiro, legal ou político envolvendo terceiros (governo, empresas e fundações privadas, etc.) foi declarado para nenhum aspecto do trabalho submetido (incluindo, mas não se limitando a subvenções e financiamentos, participação em conselho consultivo, desenho de estudo, preparação de manuscrito, análise estatística, etc.).

\section{Referências}

1. Lei $n^{\circ} 11.788$, de 25 de setembro de 2008 (Brasil). Dispõe sobre o estágio de estudantes; altera a redação do art. 428 da Consolidação das Leis do Trabalho - CLT, aprovada pelo DecretoLei no 5.452, de 10 de maio de 1943, e a Lei no 9.394, de 20 de dezembro de 1996; revoga as Leis nos 6.494, de 7 de dezembro de 1977, e 8.859, de 23 de março de 1994, o parágrafo único do art. 82 da Lei no 9.394, de 20 de dezembro de 1996, e o art. 60 da Medida Provisória no 2.164-41, de 24 de agosto de 2001; e dá outras providências. [Internet]. Diário Oficial da União. Disponível em: http://www.planalto.gov.br/ccivil_03/_ato2007-2010/2008/lei/ $\underline{111788 . \mathrm{htm}}$
2. Silva DJ, Ros MAD. Inserção de profissionais de fisioterapia na equipe de saúde da família e Sistema Único de Saúde: desafios na formação. Cien saúde coletiva. 2007;12(6):1673-81. https://doi. org/10.1590/S1413-81232007000600028

3. Resolução $n^{\circ}$ 559, de 15 de setembro de 2017 (Brasil). Recomendações do CNS à proposta de DCN para o Curso de Fisioterapia. [Internet]. Diário Oficinal de União. Disponível em: https://conselho.saude.gov.br/resolucoes/2017/Res0559.pdf

4. Santana TC, Pimenta MAA. Avaliação no Estágio em Fisioterapia sob a Ótica de Professores e Estudantes. Meta: Avaliação [Internet]. 2013;5(15):272-97. Disponível em: https://revistas. cesgranrio.org.br/index.php/metaavaliacao/article/view/166

5. Teixeira LJ, Oliveira MAC. Estágios curriculares em fisioterapia. Fisioterapia Brasil. 2007;8(1):57-63. https://doi.org/10.33233/ fb.v8i1.1746

6. Seriano KN, Muniz VRC, Carvalho MEIM. Percepção de estudantes do curso de fisioterapia sobre sua formação profissional para atuação na atenção básica no Sistema Único de Saúde. Fisioter. Pesqui. 2013;20(3):250-5. https://doi.org/10.1590/ \$1809-29502013000300009

7. Domigues RCL, Amaral E, Zeferino AMB. Os diferentes olhares na avaliação de alunos em estágio clínico supervisionado. Rev. Assoc. Med. Bras. 2009;55(4):458-62. https://doi.org/10.1590/ S0104-42302009000400023

8. Colliselli L, Tombini LHT, Leba ME, Reibnitz KS. Estágio curricular supervisionado: diversificando cenários e fortalecendo a interação ensino-serviço. Rev. bras. enferm. 2009;62(6):932-7. https://doi.org/10.1590/S0034-71672009000600023

9. Araújo FRO, Caldas MAJ, Batiston AP, Nashala Neto E, Ribeiro KSQS, Rocha VM, et al. Estágio curricular para os cursos de Graduação em Fisioterapia: recomendação da ABENFISIO. Fisioterapia Brasil [Internet]. 2010;11(4):12-5. Disponível em: https://www.portalatlanticaeditora.com.br/index.php/ fisioterapiabrasil/article/download/1595/2743

10. Lei $n^{\circ} 4$, de 19 de fevereiro de 2002 (Brasil). Institui Diretrizes Curriculares Nacionais do Curso de Graduação em Fisioterapia. [Internet]. Diário Oficial da União. Disponível em: http://portal. mec.gov.br/cne/arquivos/pdf/CES042002.pdf

11. Resolução 559, de 18 de setembro de 2017 (Brasil). Dispõe sobre as recomendações do Conselho Nacional de Saúde à proposta de Diretrizes Curriculares Nacionais do Curso de Graduação em Fisioterapia. [Internet]. Disponível em: https:// conselho.saude.gov.br/resolucoes/2017/Res0559.pdf

12. Resolução $n^{\circ}$ 431, de 27 de setembro de 2013 (Brasil). Dispõe sobre o exercício acadêmico de estágio obrigatório em Fisioterapia. [Internet]. Diário Oficial da União. Disponível em: https://www.coffito.gov.br/nsite/?p=3193 
13. Resolução $n^{\circ} 444$, de 26 de abril de 2014 (Brasil). Altera a Resolução COFFITO n 387/2011, que fixa e estabelece os Parâmetros Assistenciais Fisioterapêuticos nas diversas modalidades prestadas pelo fisioterapeuta. [Internet]. Diário Oficial da União. Disponível em: https://www.coffito.gov.br/ nsite/?p=3208

14. Resolução $n^{\circ} 139$, de 28 de novembro de 1992 (Brasil). Dispõe sobre as atribuições do Exercício da Responsabilidade Técnica nos campos assistenciais da Fisioterapia e da Terapia Ocupacional e dá outras providências. [Internet]. Diário Oficial da União. Disponível em: https://www.coffito.gov.br/nsite/?p=2897

15. Resolução $n^{\circ} 153$, de 30 de novembro de 1993 (Brasil). Inclui Inciso V, no art. $7^{\circ}$. da Resolução Coffito 139, de 18.11.1992 (D.O.U. de 26.11.92), fixando a relação máxima de preceptor/ acadêmico, quando o estágio curricular for promovido diretamente por Instituição de Ensino Superiores. [Internet]. Diário Oficial da União. Disponível em: https://www.coffito.gov.br/ nsite/?p=2911

16. Gaida JE, Maloney S, Morgan P. Clinical incidents involving students on placements: an analysis of incidents reports to identify potential risk factors. Physiotherapy. 2015;101(2):219-25. https://doi.org/10.1016/j.physio.2014.06.006

17. Pereira AMA, Alves TP. A autonomia na disciplina estágio curricular supervisionado [Internet]. XI Congresso Brasileiro de Ensino Superior à Distância; 2014; Florianópolis, SC. Disponível em: http://esud2014.nute.ufsc.br/anais-esud2014/files/ pdf/127938.pdf

18. Gribble N, Ladyshewsky RK, Parsons R. Fluctuations in the emotional intelligence of therapy students during clinical placements: implications for educators, supervisors, and students. J Interprof Care. 2017;31(1):8-17. https://doi.org/10.1080/1356182 $\underline{0.2016 .1244175}$

19. Hilton R, Morris J. Student placements-is there evidence supporting team skill development in clinical practice settings?. J Interprof Care. 2001;15(2):171-83. https://doi. org/10.1080/13561820120039892

20. Larin H, Wessel J, Al-Shamlan A. Reflections of physiotherapy in the United Arab Emirates during their clinical placements: A qualitative study. BMC Med Educ. 2005;5(1):3. https://doi. org/10.1186/1472-6920-5-3

21. Gaiad TP, Sant'Ana DMG. Análise da eficácia do estágio supervisionado em fisioterapia na formação profissional: uma visão do egresso. Arquivo de Ciências da Saúde da UNIPAR [Internet]. 2005;9(3):65-70. https://www.revistas.unipar.br/index. php/saude/article/view/200/174
22. Boucaut R. OHS students: Reaching a decision about hosting placements. Physiother Theory Pract. 2008;24(1):43-53. https:// doi.org/10.1080/09593980701686658

23. Gustafsson L, Brown T, McKinstry C, Caine AM.

Pratice educacion: A snapshot from Australian university programmes. Aust Occup Ther J. 2017;64(2):159-69. https://doi. org/10.1111/1440-1630.12337

24. Mello AF, Almeida Filho N, Ribeiro RJ. Por uma universidade socialmente relevante. Atos de Pesquisa em Educação. 2009;4(3):292-302. http://dx.doi.org/10.7867/1809$\underline{0354.2009 v 4 n 3 p 292-302}$

25. Barbosa CR, Mourão ARC, Piatti NCTP, Torres RM, Silva MF, Dantas LCS. Atenção integral e integração ensino-serviço no estágio hospitalar de Fisioterapia: relato de experiência. Cad. Edu, Saúde e Fis [Internet]. 2017;4(8):89. Disponível em: http://revista. redeunida.org.br/ojs/index.php/cadernos-educacao-saudefisioter/article/view/1501

26. Viana RT, Moreira GM, Melo LTM, Sousa NP, Brasil ACO, Abdon APV. O estágio extracurricular na formação profissional: a opinião dos estudantes de Fisioterapia. Fisioter Pesq. 2012;19(4):339-44. https://doi.org/10.1590/S1809-29502012000400008

27. Robson M, Kitchen SS. Exploring physiotherapy students' experiences of interprofessional collaboration in the clinical setting: A critical incident study. J Interprof Care. 2007;21(1):95109. https://doi.org/10.1080/13561820601076560

28. Pedra AO, Blandino RSP, Ferrari M, Reisen H, Freitas GKFF. Aproximação da formação do fisioterapeuta na atenção básica em saúde. Cad. Edu Saúde e Fis [Internet]. 2017;4(8):57. Disponível em: http://revista.redeunida.org.br/ojs/index.php/ cadernos-educacao-saude-fisioter/article/view/1449

29. Maciel RV, Silva PTG, Sampaio RF, Drummond AF. Teoria, prática e realidade social: uma perspectiva integrada para o ensino de Fisioterapia. Fisioterapia em Movimento [Internet]. 2005;18(1):11-7. Disponível em: https://periodicos.pucpr.br/index. php/fisio/article/download/18522/17956

30. Batiston AP, Bonilha LAS, Ferrari FP, Medeiros AA, Duenha C, Grosseman S, et al. Implantação de uma nova proposta pedagógica para o estágio supervisionado em fisioterapia na atenção básica: relato de experiência. Cad. Edu Saúde e Fis [Internet]. 2017;4(8):48-55. Disponível em: http://revista. redeunida.org.br/ojs/index.php/cadernos-educacao-saudefisioter/article/view/960/pdf_65 